\title{
Automation of eWeLink Based Fresh Bread Dough System
}

\section{Otomatisasi Sistem Adonan Roti Segar Berbasis eWeLink}

\author{
Muhammad Sofyan ${ }^{(1)}$, Dwi Hadidjaja Rasjid Saputra ${ }^{(2)}$ \\ muh.sofyanarya91@ gmail.com ${ }^{(1)}$; dwihadidjaja1@umsida.ac.id ${ }^{(2)}$ \\ Teknik Elektro, Universitas Muhammadiyah Sidoarjo, Indonesia
}

\begin{abstract}
The process of plain bread dough without sugar after the fermentation process is then left to stand for a certain time manually or modern. The process of developing plain bread dough without sugar can be done by using yeast which is widely sold in the market. The yeast is mixed evenly into the dough, then covered with a cloth and left for a certain time until the dough of plain bread without sugar expands. The factors that influence the development of unsweetened bread dough are the right amount of yeast, temperature and humidity also determine the development process of the bread dough without sugar. If the supporting factors are not suitable, it can cause the plain bread dough without sugar to fail to expand. By using the automation system for bread dough without sugar based on ewelink, it can reduce the failure rate during the development process of bread dough without sugar with optimal results.
\end{abstract}

Keywords - eWelink, Moisture; Yeast; Temperature; Sugarless; Time

\begin{abstract}
Abstrak. Proses adonan roti tawar tanpa gula setelah proses fermentasi, selanjutnya didiamkan dalam batas waktu tertentu secara manual ataupun modern. Proses pengembangan adonan roti tawar tanpa gula dapat dilakukan dengan menggunkan ragi yang banyak dijual dipasaran. Ragi tersebut dicampur kedalam adonan secara merata, selanjutnya ditutup menggunakan sehelai kain dan didiamkan selama waktu tertentu sampai adonan roti tawar tanpa gula menggembang. Faktor yang mempengaruhi pengembangan adonan roti tawar tanpa gula adalah takaran ragi yang tepat, suhu dan kelembaban juga menentukan proses pengembangan adonan roti tawar tanpa gula. Bila faktor pendukung tidak sesuai dapat mengakibatkan adonan roti tawar tanpa gula gagal mengembang. Dengan menggunakan atomatisasi sistem adonan roti tawar tanpa gula yang berbasis ewelink dapat memperkecil tingkat kegagalan saat proses pengembangan adonan roti tawar tanpa gula dengan hasil yang optimal.
\end{abstract}

Kata Kunci-eWelink; Kelembaban; Ragi; Suhu; Tanpa Gula; Waktu

\section{Pendahuluan}

Pengembang adonan roti tanpa gula pada umumnya digunakan untuk membantu proses pengembangan dengan tujuan untuk mendapatkan kualitas yang optimal pada roti tanpa gula[1][2]. Proses fermentasi merupakan proses dimana adonan roti yang telah di buat selanjutnya didiamkan, hal ini dapat dilakukan secara manual maupun modern, dengan tujuan untuk memperoleh roti yang berkualitas optimal dan saat dipanggang dapat mengembang secara optimal.

Proses pengembangan roti tanpa gula menggunakan metode Value Engineering (VE) [3], dan proses pengembangan roti tanpa gula juga menggunakan metode Sistem Kontrol PID [4], serta menggunakan Arduino Uno [5]. Proses pengembangan adonan roti dapat dilakukan secara manual memakai ragi. Tujuan ragi sebagai campuran untuk mengembangkan adonan roti tawar tanpa gula [6]. Perkembangan adonan roti mengalami proses pengembangan dengan menggunakan mengaturan waktu yang berbeda, tetapi menggunakan pengaturan suhu dan kelembaban tetap [7][8][9].

Thermostat Hygrostat berperan penting pada proses pengembangan adonan roti tawar tanpa gula [10]. Dengan menggunakan modul Sonoff TH10/TH16 dan Temperature Smart Home sebagai Sensor Suhu Kelembaban [11]. Faktor yang mempengaruhi proses pengembangan adonan roti tawar tanpa gula membutuhkan komposisi ragi yang tepat, suhu dan kelembapan ruangan yang stabil serta saat proses pengembangan. Agar mendapatkan hasil adonan yang dapat mengembang dengan optimal maka perlu dilakukan proses otomatisasi pada mesin pengembang adonan 
roti. Dengan menggunakan atomatisasi mesin pengembang adonan roti tawar tanpa gula, maka dapat membantu secara optimal pada proses adonan. Secara efisien dapat memantau waktu proses pengembangan adonan dari jarak jauh. Dngan menggunakan eWelink dapat mengirimkan pesan peringatan/notifikasi pada pembuat adonan roti tawar tanpa gula sampai selesai.

\section{A. Rancangan sistem}

\section{Metode}

Rancangan sistem dilakukan melalui beberapa tahap proses pengujian, meliputi perencanaan perangkat lunak dan perangkat keras. Perangkat keras yang digunakan meliputi Relay [12][13][14][15], Wi-Fi Hotspot [16], penggunaan control timer [17]. Perangkat keras tersebut berhubungan dengan permasalahan objek yang akan dilakukan pengujian. MCB berperan penting sebagai pengaman arus lebih dan hubung singkat (short circuit) [18].

\section{B. Perancangan perangkat lunak}

Perancangan perangkat lunak pertama dilakukan proses install aplikasi eWeLink berbasis Android pada Smartphone, bentuk tampilan awal eWelink ditunjukkan pada Gambar 1.

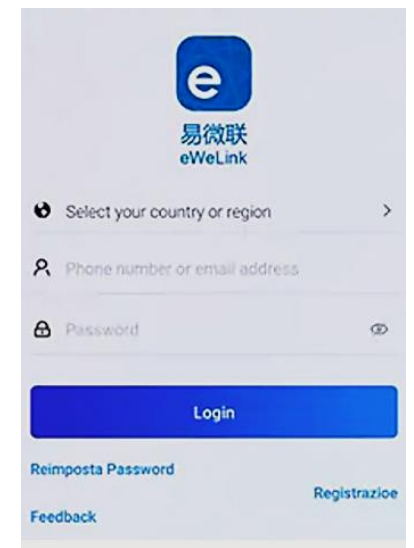

Gambar 1. Tampilan awal Software eWeLink

\section{Perancangan perangkat keras}

Perancangan perangkat keras meliputi komponen elektronika antara lain SOnOff TH10/TH16 dan Temperatur Smart Home, Sensor Suhu Kelembaban yang dihubungkan ke control module ThermoHygrostat 2 in 1 Type STC 3028, relay control sebagai kontak bantu serta menggunakan buzzer alarm sebagai notifikasi alarm pewaktu. Bentuk perancangan perangkat keras dalam bentuk blok diagram ditunjukkan pada Gambar 2.

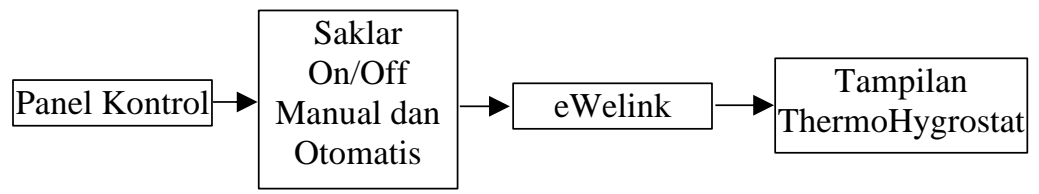

Gambar 2. Blok diagram Otomatisasi Sistem Adonan Roti Tawar Tanpa Gula Berbasis eWeLink

\section{HaSil dan Pembahasan}

\section{Pengujian Perangkat Lunak (Software)}

Aplikasi eWeLink digunakan untuk pengujian perangkat lunak. Pembacaan suhu dan kelembaban ruang saat proses pengembangan adonan dilakukan oleh sensor suhu dan kelembaban. Data yang diperoleh saat pengujian dengan menggunakan modul SOnOff TH10/TH16 dapat mengirim dan menerima hasil pembacaan data saat alat dioperasikan. Tampilan data diterima berupa pesan pada smartphone Android pemilik ditunjukkan pada Tabel 1.

Dari pengujian modul SOnOff TH10 / TH16 berfungsi dengan baik, saat dioperasikan secara otomatis. Namun terdapat selisih hasil pembacaan pada modul SOnOff TH10/TH16 dibanding dengan hasil pembacan Thermohygrometer analog THR7. Hasil pengujian modul SOnOff TH10/TH16 secara otomatis ditunjukkan pada Tabel 2.

Tabel 1. Hasil Pengujian Modul SOnOff TH10 / TH16 Secara Manual 
Procedia of Engineering and Life Science Vol. 1. No. 2 Juni 2021

Seminar Nasional \& Call Paper Fakultas Sains dan Teknologi (SENASAINS 2nd)

Universitas Muhammadiyah Sidoarjo

\begin{tabular}{|c|c|c|c|}
\hline Ke- & \multicolumn{2}{|c|}{ Setting Timer (Detik) } & Pengiriman Notifikasi \\
\hline 1 & 960 & (16 menit) & Berhasil \\
\hline 2 & 1020 & (17 menit) & Berhasil \\
\hline 3 & 1080 & (18 menit) & Berhasil \\
\hline 4 & 1140 & (19 menit) & Berhasil \\
\hline 5 & 1200 & (20 menit) & Berhasil \\
\hline 6 & 1260 & (21 menit) & Berhasil \\
\hline 7 & 1320 & (22 menit) & Berhasil \\
\hline 8 & 1380 & (23 menit) & Berhasil \\
\hline 9 & 1440 & (24 menit) & Berhasil \\
\hline 10 & 1500 & (25 menit) & Berhasil \\
\hline
\end{tabular}

Tabel 2. Hasil Pengujian Modul SOnOff TH10/TH16 Secara Otomatis

\begin{tabular}{|c|c|c|c|c|c|c|c|c|c|c|}
\hline \multirow{3}{*}{ Ke } & \multirow{2}{*}{\multicolumn{2}{|c|}{ Nilai Uji }} & \multicolumn{8}{|c|}{ Hasil Pembacaan } \\
\hline & & & \multicolumn{2}{|c|}{$\begin{array}{c}\text { Thermohygrometer } \\
\text { Analog THR7 }\end{array}$} & \multicolumn{2}{|c|}{ Modul SOnOff TH 10/16 } & \multicolumn{2}{|r|}{ Selisih } & \multicolumn{2}{|c|}{ Ketepatan Pembacaan } \\
\hline & $\begin{array}{l}\text { Suhu } \\
\left({ }^{\circ} \mathrm{C}\right)\end{array}$ & $\begin{array}{c}\text { Kelembaban } \\
(\%)\end{array}$ & $\begin{array}{l}\text { Suhu } \\
\left({ }^{\circ} \mathrm{C}\right)\end{array}$ & $\begin{array}{c}\text { Kelembaban } \\
(\%)\end{array}$ & $\begin{array}{l}\text { Suhu } \\
\left({ }^{\circ} \mathrm{C}\right)\end{array}$ & $\begin{array}{c}\text { Kelembaban } \\
(\%)\end{array}$ & $\begin{array}{l}\text { Suhu } \\
\left({ }^{\circ} \mathrm{C}\right)\end{array}$ & $\begin{array}{c}\text { Kelembaban } \\
(\%)\end{array}$ & $\begin{array}{l}\text { Suhu } \\
\left({ }^{\circ} \mathrm{C}\right)\end{array}$ & $\begin{array}{c}\text { Kelembaban } \\
(\%)\end{array}$ \\
\hline 1 & 33 & 73 & 33 & 73 & 32,8 & 72,8 & 0,2 & 0,2 & 99,394 & 99,726 \\
\hline 2 & 34 & 74 & 34 & 74 & 33,9 & 73,7 & 0,1 & 0,3 & 99,706 & 99,595 \\
\hline 3 & 35 & 75 & 35 & 75 & 34,8 & 74,8 & 0,2 & 0,2 & 99,429 & 99,733 \\
\hline 4 & 36 & 76 & 36 & 76 & 35,8 & 759 & 0,2 & 0,1 & 99,444 & 99,868 \\
\hline 5 & 37 & 77 & 37 & 77 & 36,8 & 76,8 & 0,2 & 0,2 & 99,459 & 99,74 \\
\hline 6 & 38 & 78 & 38 & 78 & 37,9 & 77,9 & 0,1 & 0,1 & 99,737 & 99,872 \\
\hline 7 & 39 & 79 & 39 & 79 & 38,9 & 78,8 & 0,1 & 0,2 & 99,744 & 99,747 \\
\hline 8 & 40 & 80 & 40 & 80 & 39,9 & 79,8 & 0,1 & 0,2 & 99,75 & 99,75 \\
\hline 9 & 41 & 81 & 41 & 81 & 40,8 & 80,8 & 0,2 & 0,2 & 99,512 & 99,753 \\
\hline 10 & 42 & 82 & 42 & 82 & 41,8 & 81,8 & 0,2 & 0,2 & 99,524 & 99,756 \\
\hline
\end{tabular}

\section{D.E. Pengujian Perangkat Keras (Hardware)}

Pengujian perangkat keras dilakukan pada komponen untuk mengetahui dan memastikan bahwa komponen dapat bekerja dan berfungsi dengan baik. Pengujian perangkat keras ini dilakukan Thermohygrostat STC3028. Pengujian Thermohygrostat STC3028 sebagai pengukur suhu dan kelembaban dilakukan dengan cara memasukkan ujung sensor ke dalam ruang pengembangan adonan roti tawar tanpa gula. Selanjutnya ruang pengembangan diatur suhu dan kelembaban, dengan cara mengalirkan uap panas ke dalam ruangan kemudian dilakukan pengukuran suhu dan kelembaban. Hasil Pengujian Thermohygrostat STC3028 ditunjukkan pada Tabel 3.

Tabel 3. Hasil Pengujian Thermohygrostat STC3028

\begin{tabular}{|c|c|c|c|c|c|c|c|c|c|c|}
\hline \multirow{3}{*}{ Ke } & \multirow{2}{*}{\multicolumn{2}{|c|}{ Nilai Uji }} & \multicolumn{8}{|c|}{ Hasil Pembacaan } \\
\hline & & & \multicolumn{2}{|c|}{$\begin{array}{c}\text { Thermohygrometer } \\
\text { Analog THR7 }\end{array}$} & \multicolumn{2}{|c|}{ Modul SOnOff TH 10/16 } & \multicolumn{2}{|r|}{ Selisih } & \multicolumn{2}{|c|}{ Ketepatan Pembacaan } \\
\hline & $\begin{array}{l}\text { Suhu } \\
\left({ }^{\circ} \mathrm{C}\right)\end{array}$ & $\begin{array}{c}\text { Kelembaban } \\
(\%)\end{array}$ & $\begin{array}{l}\text { Suhu } \\
\left({ }^{\circ} \mathrm{C}\right)\end{array}$ & $\begin{array}{c}\text { Kelembaban } \\
(\%)\end{array}$ & $\begin{array}{l}\text { Suhu } \\
\left({ }^{\circ} \mathrm{C}\right)\end{array}$ & $\begin{array}{c}\text { Kelembaban } \\
(\%)\end{array}$ & $\begin{array}{l}\text { Suhu } \\
\left({ }^{\circ} \mathrm{C}\right)\end{array}$ & $\begin{array}{c}\text { Kelembaban } \\
(\%)\end{array}$ & $\begin{array}{l}\text { Suhu } \\
\left({ }^{\circ} \mathrm{C}\right)\end{array}$ & $\begin{array}{c}\text { Kelembaban } \\
(\%)\end{array}$ \\
\hline 1 & 33 & 73 & 33 & 73 & 33,1 & 73,1 & $-0,1$ & $-0,1$ & 99,679 & 99,863 \\
\hline 2 & 34 & 74 & 34 & 74 & 34,2 & 74,1 & $-0,2$ & $-0,1$ & 99,412 & 99,865 \\
\hline 3 & 35 & 75 & 35 & 75 & 35,1 & 75,1 & $-0,1$ & $-0,1$ & 99,714 & 99,867 \\
\hline 4 & 36 & 76 & 36 & 76 & 36,1 & 76,3 & $-0,1$ & $-0,3$ & 99,722 & 99,868 \\
\hline 5 & 37 & 77 & 37 & 77 & 37,1 & 77,2 & $-0,1$ & $-0,2$ & 99,730 & 99,605 \\
\hline 6 & 38 & 78 & 38 & 78 & 38,2 & 78,2 & $-0,2$ & $-0,2$ & 99,747 & 99,740 \\
\hline 7 & 39 & 79 & 39 & 79 & 39,2 & 79,3 & $-0,2$ & $-0,3$ & 99,487 & 99,744 \\
\hline 8 & 40 & 80 & 40 & 80 & 40,2 & 80,2 & $-0,2$ & $-0,2$ & 99,500 & 99,620 \\
\hline 9 & 41 & 81 & 41 & 81 & 41,1 & 81,2 & $-0,1$ & $-0,2$ & 99,756 & 99,753 \\
\hline 10 & 42 & 82 & 42 & 82 & 42,1 & 82,3 & $-0,1$ & $-0,3$ & 99,762 & 99,634 \\
\hline
\end{tabular}




\section{E.F. Pengujian pengiriman peringatan / notifikasi}

Pengujian Peringatan/Notifikasi ini dilakukan untuk mengetahui apakah sistem dapat mengirim notifikasi / peringatan ke smartphone operator dan menyalakan buzzer alarm ketika proses pengembangan adonan roti (proofing) sudah selesai. Berikut hasil pengujian yang dilakukan untuk mengetahui fungsi pengiriman notifikasi dari alat ke smartphone pengguna yang ditunjukkan pada Tabel 4.

Tabel 4. Hasil Uji Fungsi Penerimaan Notifikasi

\begin{tabular}{ccc} 
Ke & Setting Timer (Detik) & Pengiriman Notifikasi \\
\hline 1 & 960 & Berhasil \\
2 & 1020 & Berhasil \\
3 & 1080 & Berhasil \\
4 & 1140 & Berhasil \\
5 & 1200 & Berhasil \\
6 & 1260 & Berhasil \\
7 & 1320 & Berhasil \\
8 & 1380 & Berhasil \\
9 & 1440 & Berhasil \\
10 & 1500 & Berhasil \\
\hline
\end{tabular}

\section{KESIMPULAN}

Mesin otomatisasi pengembang adonan roti tawar tanpa gula berbasis eWeLink menggunakan tiga modul kontrol utama antara lain modul Sonoff TH10/TH16 dan Thermohygrostat STC3028 sebagai pengatur suhu dan kelembaban ruang pengembangan adonan roti tawar tanpa gula. Dalam pengujiannya mesin otomasisasi dapat bekerja dengan optimal.

Sistem kontrol pada mesin otomatisasi pengembang adonan roti tawar tanpa gula dapat bekerja dengan baik dalam pembacaan suhu dan kelembaban ruang serta dapat mengirimkan data hasil pembacaan secara real-time ke smartphone pemilik.

\section{UCAPAN TERIMA KASIH}

Terima kasih kepada Bengkel Las M.U Stainless Steel yang telah membantu dalam pembuatan mesin otomatisasi pengembang adonan roti tawar tanpa gula ini. Terima kasih juga kepada seluruh Civitas Academia Fakultas Sains dan Teknologi Universitas Muhammadiyah Sidoarjo yang sudah mendukung dalam penelitian ini.

\section{REFERENSI}

[1] S. Syahrorini and D. Hadidjaja, "Aplikasi Alat Ukur Partikulat dan Suhu Berbasis IoT," Jurnal Dinamik, vol. 25, no. 01, pp. 1-9, 2020.

[2] "Penentuan Konsentrasi Ragi Pada Pembuatan Roti," Determining of Yeast Concentration on Bread Making, vol. 2, no. 1, pp. 71-77, 2019.

[3] R. Hidayat, A. Arendra and S. Akhmad, "Pengembangan Mesin Fermentasi Roti Menggunakan Pendekatan Value Engineering (VE)," Spektrum Industri, vol. 12, no. 1, pp. 1-112, 2014.

[4] N. Yuliarmas, S. Aisyah and H. Toar, "Implementasi Kontrol PID pada Mesin Pengembang Roti," Rekayasa Elektrika, vol. 11, no. 3, pp. 79-122, 2015.

[5] H. I. Islam, N. Nabilah, S. S. Atsaurry, D. H. Saputra, G. M. Pradipta, A. Kurniawan, H. Syafutra, I. and I. , "Sistem Kendali Suhu dan Pemantauan Kelembaban Udara Ruangan Berbasis Arduino UNO dengan Menggunakan Sensor DHT22 dan Passive Infrared (PIR)," PROSIDING SEMINAR NASIONAL FISIKA, vol. V, 2016.

[6] M. D. Ariyana, S. Widyastuti, N. B. R. Handayani, W. Werdiningsih and N. Rahayu, "Pengaruh Penambahan Hidrokoloid Iota Karaginan untuk Meningkatkan Kualitas, Keamanan dan Daya Simpan Roti," Pro Food (Jurnal Ilmu dan Teknologi Pangan), vol. 3, no. 1, pp. 186-193, 2017. 
[7] K. Suharno, C. Pramono, R. C. Aditama and F. Hilmy, "Pengaruh Heater pada Kelembaban dan Suhu di dalam Proofer Terhadap Perkembangan Roti," Journal of Mechanical Engineering, vol. 3, no. 1, pp. 15-21, 2019.

[8] A. W. Indrawan, A. Achmad and K. Riyadi, "Pengaturan Suhu dan Kelembaban pada Ruang Proofer Berbasis Mikrokontroler Arduino," Seminar Nasional Hasil Penelitian \& Pengabdian Kepada Masyarakat (SNP2M), pp. 122-128, 2020.

[9] B. S. Suryatna, "Peningkatan Kelembutan Tekstur Roti Melalui Fortifikasi Rumput Laut Euchema Cottoni," Teknobuga, vol. 2, no. 2, pp. 18-25, 2015.

[10] D. Musrinaldi and D. , "Pembuatan Thermostat Sebagai Alat Pengatur Suhu Di Ruangan Penyimpanan Arsip," Jurnal Ilmu Informasi Perpustakaan dan Kearsipan, vol. 7, no. 2, pp. 213-215, 2019.

[11] L. SONOFF technologies Co., "SONOFF," SONOFF Official, 26 October 2018. [Online]. Available: https://sonoff.tech/product/wifi-diy-smart-switches/th10-th16\#tab-download_tab. [Accessed 2 November 2019].

[12] B. M. Arsyad, A. Sofwan and A. Nugroho, "Perancangan Sistem Kontrol Over/Under Voltage Relay Berbasis Mikrokontroler pada Saluran Tegangan 220VAC," Transient , vol. 8, no. 1, pp. 85-92, 2019.

[13] D. Almanda and H. Yusuf, "Perancangan Prototype Proteksi Arus Beban Lebih Pada Beban DC Menggunakan Mikrokontroller," Elektum, vol. 14, no. 2, pp. 25-34, 2017.

[14] M. D. Danu Wiguna, I. P. S. Arsa and I. G. Ratnaya, "Pengembangan Media Pembelajaran Trainer Pengendali Elektromagnetik Berbasis Smart Relay pada Instalasi Motor Listrik," Pendidikan Teknik Elektro Undiksha, vol. 9, no. 3, pp. 203-212, 2020.

[15] S. Aiyub, Y. and A. Kasyfi, "Penggunaan Relay Arus Lebih Tipe Sel-351A Sebagai Proteksi Pada Motor Induksi 3 Phasa," Proceeding Seminar Nasional Politeknik Negeri Lhokseumawe, vol. 2, no. 1, pp. 287-298, 2018.

[16] F. Ardianto, B. Alfaresi and R. A. Yuansyah, "Jaringan Hotspot Berbasis Mikrotik Mengunakan Metode Otentikasi Pengguna (User)," Jurnal Surya Energi, vol. 2, no. 2, pp. 166-171, 2018.

[17] D. Aryono and M. , "Pemakaian Timer pada Pengereman Dinamik Motor Induksi Rotor Sangkartiga Phasa," Jurnal Teknik Mahasiswa Unesa, vol. 3, no. 1, pp. 29-33, 2012.

[18] D. G. Primadhika, P. M. Djaohar and H. Firdaus, "Perubahan Suhu Lingkungan Terhadap Waktu Trip Pada Mini Circuit Breaker 6A Tipe C," Pengaruh Kenaikan Besar Arus Listrik, vol. 5, no. 1, pp. 6-13, 2020. 